\section{Barex SciencePark Research, Organization \& Counseling \\ Global Journal of Foreign Language Teaching}

Volume 7, Issue 3, (2017) 107-115

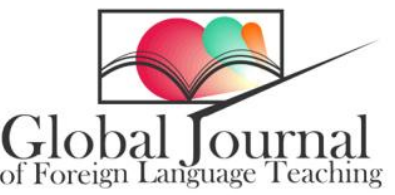

www.gjflt.eu

\title{
Revival of Persian language in today writings based on morphological system of fifth century texts
}

\begin{abstract}
Sara Mohammadi Moghaddam*, Payame Noor University of Mashhad, Iran.
\end{abstract}
Mahmoud Ramazanzadeh Lak, Payame Noor University of Mashhad, Iran.

\section{Suggested Citation:}

Moghaddam, S. M. \& Lak, M. R. (2017). Revival of Persian language in today writings based on morphological system of fifth century texts. Global Journal of Foreign Language Teaching. 7(3), 107-115.

Received from November 16, 2016; revised February 26, 2017; accepted April 02, 2017.

Selection and peer review under responsibility of Assoc. Prof. Dr. Ali Rahimi, Bangkok University, Thailand.

${ }^{\circledR} 2017$ SciencePark Research, Organization \& Counseling. All rights reserved.

\begin{abstract}
This paper will investigate 'Making the word of Persian literature in the fifth century Hijri and comparison with Today literature' and is based on the model of the theory of Chomsky's transformation. The research tools in this article are from the books of Bayhaqi, Siyasatnama and Chahar - Maghaleh from fifth centuryliterature. The two books 'Khorshide Maghreb' and 'sad sal dastan nevisi dar Iran', which todayare paragraphed prose is given. The results of the hypothesis in this paper show the following: 1) a simple word frequencyin fifth century texts with contemporary Persian prose texts and derivativecompound comprising more than words; 2 ) with the help of a revival of a ffixes and word combinations, texts used in the fifth century that are in dedine and forgotten can be used today, in the words of Persian literature; 3) Persian is a suffix language.
\end{abstract}

Keywords: Morphology, prefix, affixes-simple, today Persian writings, fifth century texts.

\footnotetext{
* ADDRESS FOR CORRESPONDENCE: Sara, Mohammadi, Mogha ddam, Paya me Noor Unive rsity of Mash had, I ran. E-mail address: sa ra.m371@yahoo.com / Tel.: +4-345-43-4232
} 


\section{Introduction}

Fifth century texts can expand the scope and interpretation of text and material combinations of linguistic features such as compositing, and the word synergy has benefited. Deliberation in the choice of words and combinations of the two to be investigated, 'Understanding the meaning of words and considering the use of a writer from the needless waste and the use of synonyms and words and on the other hand will be removed and eloquent prose is manifested'(Tabatabai, 2001).

The frequency of words and interpretations in the Persian language spoken in Persian dictionaries is not registered. Hence, sometimes it is described as the history of ancient Persian literature Bayhaqi, and sometimes it is difficult to explain the meaning given in the dictionary for the word mentioned. While using common sense among people, especially speakers Khorasani, can be realised in the structure of words and expressions, and the ambiguity and confusion in the meaning ruined. That is why the dialects in literary texts are of great help to solve some problems, 'especially because dialects spoken dialects of Persian Khorasan often finish fourth, fifth and sixth centuries AD' (Zomorodian, 2004).

In this article, we have tried to explore the simple words used in texts of the fifth century and their efforts to revitalise the richness of Persian add, on the other hand derivative of the links in the active mode and the word combination.

\subsection{The necessity and importance of research}

Persian literature of the fifth century and very valuable ancient texts can be a good source for linguistic and literary studies. For example, over-reliance on Western terms, as well as the Arabic word that has taken over our words, makes it difficult to understand the literature. Advancement of science, followed by the massive influx of science and technology to the body language Persian makes word for word the way it is tighter, because the penetration of these words in Persian words for them has gone faster than equivalent.

Persian language, culture and civilisation is a great new face for expressing new concepts.

In such a situation, one way of facing the Farsi language is that of the European languages (e.g., English) to adopt it as the language of science. The Persian literature should make use of it on a daily basis and sometimes the solution causes irreparable damage to the body of the Persian language and culture and national identity brings and here we must refer to their ancient literary treasures dust from the lean and rich vocabulary and expressions that take them to recover and fertilise them. The authors of the texts of the fifth century AD discovered this great mystery of linguistics, which should increase the frequency and power of the meaning of words and the words broke from different angles. So they can increase their language and we prove that the Persian language, if viewed from this perspective, is not sterile. This paper helps to clarify the meanings of words and compounds, able to understand the language of the early period, learning style and understand the causes of success or poor quality of work and the promise of spring: 'Understanding the causes of the rise and decline of prose' (Jahandideh, 1999).

In this paper, we present strategies to revive the forgotten words that fear is they, activation affixes and word combinations used in the context of the fifth century to the present and appreciate the beauty of a work in comparison with other works of importance and urgency of addressing this issue that in the end all, just reading, writing, and it just brings understanding and promote the Persian language would be added to that extent.

\subsection{Review of the literature}

This word in the West since Plato and Aristotle the philosopher and Dastourian has spread (Robbins, 1991). Including Plato's divided into two parts nominal and current. Syntactic and 
morphological analyses were further divided in the beginning. He added another class to the class, he also described the word that means the same language is used in the manufacture of biodegradable elements is significantly smaller.

The idea of 'grammar transformation germ' or briefly 'grammar transformation', the first time in 1957, the book 'Syntactic Structures' by contemporary American linguist Noam Chomsky was released, and in 1965 another book of the same linguist, known as 'aspects of the theories being' found new developments. From this time onwards, also by Chomsky and other linguists, some constantly expanding and revising theory has been carried out. In fact, the theory of grammar transformation, to explore and describe the language in the new landscape spread before the eyes of researchers.

Katamba says I generative approach is the basic unit is a morpheme (Katamba, 1993). In the early 19th century, researchers have reconstructed Indo-European language in the spotlight and Franz Bopp in 1816 and the results of their study comparing grammatical endings of words in Sanskrit, Latin, Persian and published Sir William Jones's claims about the common ancestor of these languages are confirmed. (Ibid: 3)

Kiparsky spent his time to expand vocabulary model 1972 and 1982, changes were made. The theoretical basis for this great linguist is the term foundation.

One of the theories that Marantz foods and the word were offered a theory of distributive spending was introduced in 1993. Within this theory is applicable to the Persian language, because it seems to be a certain place in the Persian language and morphological processes in areas such as fashion, done (Halle \& Marantz, 1993).

Aronouf fully in mind that we do not keep your word, 'Went to' separate the mind and the ' $A$ ' and when we can separate the word 'behavior' to make, but if we treat the mind, or a way to make new words closes.

In the essay 'Thoughts on the name of' Chomsky said that he ordered a portion of the base, which consists of rules category (= rule making group), which all tissues - are free, and vocabulary, which consists of entries where each entry is specified as a set of attributes. In addition to the basic recipe is a set of torque acting on the deep structure and surface structure is produced in the wake of the recent transformation. He set the foundation for the transformation rules of syntax (the command) are called. Command also has a set of phonological rules that operate on the surface and finally the symmetry (i.e., pronunciation) they lose (Dabirmoghadam, 2011).

McCarthy (1972) argues that the Semitic languages, words are derived from the roots of three matches, and sometimes two matches, but the language is consistent frequency Tuesday. For example, the root of the Arabic language school Tuesday compatible ' $\mathrm{kt} \mathrm{b}$ ' is derived. In addition to the above theoretical Katamba also believes in hybrid languages such as Persian and Turkish meanings of root words, affixes join constructed, but in languages such flections Semitic languages (Arabic and Hebrew) words is obtained by changing the inner root and not through the roots and affixe s to get together.

Matthews is believed to be attached to the morpheme, the words are important, so the theory Matthews also in Persian language link does not respond. Because of language concepts, linked by joining affixes to the root words (Morpheme), it is important (Mathews, 1974).

Eshghi Khorasani (2000) in his article entitled 'Investigation word Shahnameh (compound words)', which is close to the subject of this article. The paper is structured and how it is expressed only compound words with the meaning of each word, and no explanation of how the term is used.

Khormaei (2008) entitled 'Principles making new words and terms are made public', the other articles in the field of construction of words that need to be addressed. The author believes that the reason is always the most important concern of the Academy in different periods, the Persian words in both the public and experts. 
The words of ancient texts, not only in terms of the language used, but in enriching and improving the habit of writing and rhetoric, literary language. 'Explore the Persian language, literature and literary figure of the value of these works, the more of a relationship with the Persian language. Persian language, we will guard against the invasion of foreign languages in the form of the figure of the Persian retard' (Ghasemi, 1997).

\subsection{Morphological process in Persian}

The main motivation for word making, explain what is fresh and easy messaging. Furthermore, expression of feelings and emotions that a person loses is pointed. And interpretations not normally respond to them, as well as the beauty of creation and defamiliarisation. These motives are of the normal term. But there's another motive that word making will require a planned and organised. It is concerned with preserving the cultural identity of the country to certain centers, which leads remedy against the invasion of foreign words, and this is something that is involved with the Academy.

In recent decades, a number of scientists, in terms of the simple verbs to verbs have preferred compound. Simplicity that they have used verbs is divided into two groups. The first group verbs in Persian Mahjoori are not used today, it is obvious that most professional's verbs do not have exactly the same as the old concept, but in the sense of self, which is not unconnected with the old sense, have used, Tabatabai (2001).

'The most important way to build a scientific word, or change the source of the so-called fake source has gotten'. 'In Farsi as well as English, French, Arabic and many nouns or adjectives, verbs other languages must be derived in order to make it to get your problem resolved'. Another way that should be used for scientific term, taking the derivative of the verb that is used in Persian, this means that the derivative of the analogy, whether the derivatives are not used in the past or currently are not common (Bateni, 1993).

Using simple words or free can combine and develop the synergies can be passed on. But all we have 14500 free morphemes has not actually passed on synergies. So our job is to be passed on synergistic processes in simple terms derived from ancient texts and thereby provide a model for our modern word making. We have revived the moribund and instead of duplicate the current element connected to each verb means to transmit inaccurate and unclear, the use of affixes to the meaning of the word, the more original and better spread and respect the principle of linguistic economy.

\subsection{Facing the new Persian language and culture}

Precious treasures prose texts from the fifth century Persian considered the durability and authenticity of the work, to show the uniqueness of it. There are simple words and prefixes each language diversity in terms of capacity-building assistance. Fourth to sixth century's Persian language has the capacity to actually provide this feature in Modern Persian gradually disappeared. Use verbs in the combined result of lower fertility. Thus, the recovery of simple verbs and prefixes cause principle of linguistic economy and it also paves the derivation of the verb and the power of language added productivity.

The authors of the texts of the fifth century $A D$, the great secret of linguistics should be understood that the meaning of the word frequency and increased the power and influence of different angles in the word. So they can increase their language and we prove that the Persian language, if viewed from this perspective, is not sterile (Jahandideh, 1999).

\subsection{Assumptions}

This study examined the following hypotheses: 
A simple word frequency in the fifth century texts with contemporary Persian prose texts and derivative-compound comprising more than words.

With the help of a revival of affixes and word combinations used in the fifth century texts that are in decline and dementia can be used today, in the words of Persian literature.

Persian is a suffix Language.

\subsection{Methodology}

This paper is based on the Chomsky model of transformation. Vocabulary study tool is the fifth century literature. The words most history books Bayhaqi, Siyasatnama and Chahar - Maghaleh from fifth century literature. The two books Evening Sun and hundreds of fiction in Iran, which today are paragraphed prose is given. In this study we examine the words of the book have been extracted from each of the five examples cited page. First, the term structure is examined, the meaning or meanings of the terms in the fifth century literature reviewed, the different meanings of the word as a Dehkhoda culture, especially given the overwhelming proof is extracted.

Beyhaqi history more words than the other books in size and simple prose books! In simple words, as to the accuracy of the meanings and implications of seeking spiritual makeup is gone. It can be one of the most expressive and fluent prose works on the evolution of Persian prose.

A simple and free flowing prose of siasatnama book and terms of complexity and it is abundant in beautiful combinations. Four articles written for the old and the brevity and simplicity of word and phrase meaning saturated and free from verbal industries (except a few) and empty words and sentences synonymous (with the exception of a few positions) and the Connecting the intertwining strands health composition and clearly visualise the content and meaning of the words and expressions used to describe Tom and his place among the noblest of literary prose books Qaboos counts and in writing of a policy letter.

Sun and west of the modern Persian paragraphed prose has written by M. Wise. The fourteen chapters in books and on the absence of the Imam is expected task. The style of writing is more a combination of words and simple words it can be seen below.

A hundred years from paragraphed prose fiction books in Iran today. Hassan Abedini author has tried to compare stories and novels of the period and the period story from that period is noted. In writing this book, like other contemporary prose books more than words and simple combination of the words was used.

\subsubsection{Morphological descriptions of the Persian language}

Persian word grammar is divided into four categories: nouns, verbs, adjectives and adverbs. (Ahmadi Givi \& Anvari, 2008), and the construction of the four categories: simple, derived, compound and derivative-compound (Vahidian Kamyar, 2010).

\subsubsection{Extensive (simple)}

Persian word grammar is divided into four categories: nouns, verbs, adjectives and adverbs. (Ahmadi Givi \& Anvari, 2008), and the construction of the four categories: extensive, derived, compound and derivative-compound (Vahidian Kamyar, 2010).

The paper concludes with a review of the structure of words and the first research hypothesis we got to the second hypothesis that the revival of affixes and word combinations used in the literature of the fifth century and the help of the word today. 


\subsubsection{Derived}

Derived from the two types of current and non-current derivative is mentioned. As the name suggests, the current derived from the verb prefix included and non-current derivative is comprised of two types of prefixes and suffixes (Kalbasi, 1992).

\subsubsection{Compound}

In Persian word consisting of the building divided into two general categories, current and noncurrent (Shaghaghi, 2010).

\subsubsection{Derivative-compound}

Derived words - Persian literature composed in the fifth century AD, Persian literature today is like a combination of derivatives and compounds, which can be seen in the building and combine them to make the derivative. Kalbasi (1992) thus making it a subset of composite construction and a separate section for it does not have it.

\subsubsection{Fifth century text books}

In this paper, the term of the fifth century texts that is based on the word into four categories: simple, derivative, compound and derivative-compound have been divided into separate books according to the terms described above.

1.6.2.1. Word statistics of sample fifth century texts, by simple, derived, compound and derivative-compound

Table 1 shows these percent:

Simple words: $50 \%$

Derived words: $0 \%$

Compound words: $36 \%$

Derivative-compound: $14 \%$

Table 1. Word statistics of sample fifth century texts, by simple, derived, compound and derivative-compound

\begin{tabular}{lccc}
\hline Vocabulary & Siasatnama & $\begin{array}{c}\text { Chahar - } \\
\text { Maghaleh }\end{array}$ & $\begin{array}{c}\text { Beyhaqi } \\
\text { History }\end{array}$ \\
\hline Simple & 11 & 15 & 17 \\
Derived & 0 & 0 & 21 \\
Compound & 8 & 11 & 9 \\
Derivative- & 3 & 6 & 5 \\
compound & & & \\
\hline
\end{tabular}

1.6.2.2. Word statistics of sample today writings, by simple, derived, compound and derivative-compound

Table 2 shows these percent:

Simple words: $18 \%$

Derived words: $25 \%$

Compound words: $46 \%$

Derivative-compound: $11 \%$ 
Table 2. Word statistics of sample today writings, by simple, derived, compound and derivative-compound

\begin{tabular}{lcc}
\hline \multicolumn{1}{c}{ Vocabulary } & $\begin{array}{c}\text { Khorshide } \\
\text { Maghreb }\end{array}$ & $\begin{array}{c}\text { Sad Sal Dastan } \\
\text { Nevisi Dar Iran }\end{array}$ \\
\hline Simple & 5 & 3 \\
Derived & 7 & 5 \\
Compound & 13 & 11 \\
Derivative- & 3 & 5 \\
compound & & \\
\hline
\end{tabular}

1.6.2.3. Word statistics of chosen five pages of the fifth century texts

Table 3 shows these percent:

Simple words: $45 \%$

Derived words: $5 \%$

Compound words: $35 \%$

Derivative-compound: $15 \%$

Table 3. Word statistics of chosen five pages of the fifth century texts

\begin{tabular}{lccc}
\hline \multicolumn{1}{c}{ Vocabulary } & Siasatnama & $\begin{array}{c}\text { Chahar }- \\
\text { Maghaleh }\end{array}$ & $\begin{array}{c}\text { Beyhaqi } \\
\text { History }\end{array}$ \\
\hline Simple & 450 & 450 & 400 \\
Derived & 50 & 50 & 450 \\
Compound & 350 & 300 & 100 \\
Derivative-compound & 150 & 200 & 50 \\
\hline
\end{tabular}

1.6.2.4. Word statistics of chosen five pages of today writings

Table 4 shows these percent:

Simple words: $14 \%$

Derived words: $29 \%$

Compound words: $50 \%$

Derivative-compound: $7 \%$

Table 4. Word statistics of chosen five pages of today writings

\begin{tabular}{lcc}
\hline \multicolumn{1}{c}{ Vocabulary } & Khorshide Maghreb & $\begin{array}{c}\text { Sad Sal Dastan Nevisi } \\
\text { Dar Iran }\end{array}$ \\
\hline Simple & 100 & 100 \\
Derived & 200 & 200 \\
Compound & 350 & 400 \\
Derivative- & 50 & 100 \\
compound & & \\
\hline
\end{tabular}

\section{Conclusion}

This paper concludes with a review of the structure of words and the first research hypothesis we got to the second hypothesis that the revival of affixes and word combinations used in the literature of the fifth century and the help of the word today. The words that are made by combining more than 
words that can be created through derivation, meanwhile, the combined processes of derivation processes is much smaller and easier and perhaps this is why it tends to be more common in Modern Persian. But must remain unaware of the derivation and recovery simple words; compound words to help in terms of trying to be more examples noted that today there is no equivalent, or if there is either combined or additional attribute or a foreign word is used instead, like 'Nocturnal', which is the time between dawn and dawn, when today we have a word for it and finally we reached the third hypothesis is that the Persian language extension, because most of the verbs in Persian texts, there are built using prefixes and in this sense it can be said that prefix verbs in Persian literature. So check with simple words, the derivative of the compound to the conclusion that can be raised out of the Persian language and affixes and words in the word used, the productivity in your search language are important. The current prefixes, as mentioned, are of particular importance. The simple words, especially verbs in terms of the basic elements as simple words were complex.

In the end, the author concludes, the term process is a minor component of linguistic competence and it cannot be monopolised by scholars or organisations. Word of the principles that make Guyana speak the language unconsciously obeys it. Every word must be conscious of the function of making, these principles are:

To minimise the resistance of the neologism.

the application of the rules in terms of breeding and breeding

compliance with the limitations of the term

The word should be done based on the words and vocabulary. (The first word is a fundamental principle and follow the principles of the second, third and fourth principle is needed to achieve)

\section{References}

Abedini, H. (1996). Sad sal dastan nevisi dar Iran. Tehran, Iran: Tondar Publishing.

Ahmadi Givi, H. \& Anvari, H. (2008). Persian grammar (2nd ed.). Tehran, Iran: Fatemi Publications.

Asgari, L. (2006). Involved Persian words in Russian. Journal of the Academy, 29, 150-174.

Bateni, M. R. (1993). The derivation of the word. In Proceedings of the Seminar on the Persian language and the language of science. Tehran, Iran: Tehran University.

Bayhaqi, A. (2004). History of Bayhaqi and to try to correct the Dr. Ali Akbar Fayyaz and Dr. M. J. Yahaghi (4th ed.). Mashhad, Iran: Mashhad University.

Dabirmoghadam, M. (2011). Theoretical linguistics: Forma tion and development of generative grammar. Tehran, Iran: SAMT Publishing.

Ghasemi, H. (1997). Persian grammar on Bayhaqi (Unpublished Master Thesis). Department of Literature Martyr, Beheshti University, Tehran, Iran.

Hakimi, M. (2001). Khorshide maghreb (19th ed.). Tehran, Iran: Islamic Cul ture Publishing.

Halle, M. \& Martanza, A. (1993). Distributed morphology and pieces of inflection. US: MIT press.

Jahandideh, S. (1999). In the absen ce of metaphor. Rasht, Iran: Choobak Publishing.

Kal basi, I. (1992). Derivative words in Persian today. Tehran, Iran: Tehran Institute for Cultural Studies.

Katamba, F . (1993). Morphology. London, UK: Macmillan Press.

Khormaei, A. R. (2008). Principles of morphology. Journal of Language and Literature.

Mathews, P. H. (1974). Morphology. Cambridge, UK: Cambridge University Press.

Najafi, A. (2006). Culture difficulties in Persian writing (12th ed.). Tehran, Iran: Markaz Publishing.

Nezami Aroozi Samarkandi, A. (1996). Chahar maghaleh. Tehran, Iran: Diba Publishing.

Nezam-ol-molk, H. (2006). Siasatnama (6th ed.). Tehran, Iran: Sep ehr publishing.

Robbins, R. (1991). A short history of linguistics. Tehran, Iran: Markaz Publishing.

Shaghaghi, V. (2010). Foundations of spending. Tehran, Iran: SAMT Publishing. 
Moghaddam, S. M. \& Lak, M. R. (2017). Revival of Persian language in today writings based on morphological system of fifth century texts. Global Journal of Foreign Language Teaching. 7(3), 107-115.

Tabatabai, A. (2001). The need for barriers word. Magazine Publishing Knowledge, 9, 28-33.

Tabatabai, A. (2007). Spent Persian. Bokhara Journal, 63, 212-242.

Vahidian Kamyar, T. (2010). Persian of the first year of secondary school textbooks (14th ed.). Tehran, Iran: Office authored textbooks.

Zomorodian, A. (2007). Persian structure. Tehran, Iran: SAMT Publishing. 